\title{
Analyzing the Standard Deduction as a Presumptive Tax
}

\author{
JOEL SLEMROD \\ Department of Economics, University of Michigan, Ann Arbor, MI 48109, United States \\ SHLOMO YITZHAKI \\ Hebrew University
}

Key words: taxation, horizontal equity, compliance costs

\begin{abstract}
Presumptive taxes can be found in the tax system of most developing countries and make sense when the desired tax base is difficult to measure, verify, and monitor. As a substitute for the desired tax base, the presumed tax base is derived from items that can be more readily monitored. Presumed taxes can also be found in developed countries, and examples include fixed depreciation schedules in place of asset-specific measures of decline in asset value, floors on deductible expenses, and the standard deduction. The authors analyze presumptive income taxation with an ultimate goal to initiate an approach to optimal presumptive taxation. This paper begins that task by analyzing the standard deduction in the individual income tax system in the United States.
\end{abstract}

\section{Introduction}

Presumptive taxes are a pervasive element in the tax system of most, if not all, developing countries. They make sense in cases where the otherwise desirable tax base is difficult for the tax authorities to measure, verify, and monitor. A substitute for the desired base is the presumed tax base, which is derived from a formula, which may be simple or complex, based on readily observable measures. For example, instead of a tax on the income of taxi drivers, a tax may be assessed on the accumulated mileage value of the taxicab, as formerly was the case in Israel. For shopkeepers, the tax may be assessed on the square footage of the shop. The wide variety of presumptive taxes used in the developing world is nicely surveyed in Tanzi and Casanegra (1989).

The problem that presumptive taxes address-the difficulty of monitoring certain potential tax bases-is not confined to developing countries, and use of presumptive taxes-albeit with different names-is also widespread in developed countries. Examples include the use of fixed depreciation schedules in place of asset-specific measures of the decline in asset value, taxation of capital gains on a realization basis, floors on deductible expenses, and the example considered below-the standard deduction.

All taxes are presumptive, to some degree. The conceptually pure tax basewhether the flow of income, wealth, sales revenue, or something else-cannot be perfectly measured, and the tax authority is resigned to relying on some correlate 
of the concept. We label particular taxes as presumptive when the calculation of the tax base deviates in a substantial way from the ideal concept.

\section{Issues and related previous literature}

In what follows we analyze presumptive income taxation, although the issues apply to other kinds of taxation, as well. To do so we must first confront the rationale of income taxation and then the costs of enforcing income taxes.

The overriding defense of income taxation is that it facilitates a close association of tax burden with a taxpayer's ability to pay. Deviations from the income tax base cause horizontal inequity, in which two taxpayers of equal income pay different tax burdens, and vertical inequity, in which the desired association between tax burden and ability to pay is not achieved. The latter problem can be mitigated somewhat by adjusting the schedule of tax rates applied to the base, but the problem of horizontal inequity cannot be similarly mitigated. Previous attempts to integrate horizontal equity concerns into normative models of taxation have not been notably successful in either producing a widely used methodology or in providing easily operational optimal tax rules.

The resource costs of collecting taxes has recently received increasing attention. Work in the United Kingdom (Sandford, Godwin, and Hardwick, 1989) and in the United States (Slemrod and Sorum, 1984; Blumenthal and Slemrod, 1992) have documented that these resource costs are large. These studies consistently show that the budget of the tax collection agency is a small fraction of the total resource cost of collection, with the largest part being borne by taxpayers themselves.

There have been a few attempts to integrate administrative considerations into normative analysis. Yitzhaki (1979) and Wilson (1989) consider the optimal consumption tax base, where expanding the set of taxed commodities increases administrative cost but decreases the consumption distortions caused by taxing some commodities but not others. Usher (1986) and Mayshar (1991) integrate administrative considerations into more general models of optimal commodity taxation. Both Sandmo (1981) and Slemrod and Yitzhaki (1987) analyze the optimal degree of tax enforcement in a model where risk-averse taxpayers will evade taxes subject to the enforcement regime chosen. Sadka and Tanzi (1993) address related issues concerning a tax on gross assets.

Our goal in this paper is to initiate an approach to optimal presumptive taxation-that is, a normative analysis-that directly addresses the empirical fact that there are compliance and monitoring costs of taxation. There are two general categories of presumptive taxes. In the first, tax liability is based on an easily monitorable base that is highly correlated with the ideal tax base. A tax on taxicab mileage and a tax on electricity use by a laundry are examples. In many cases, the monitorable base is a specific input, and the presumptive tax is actually a tax on an input. The second category includes (effective or de facto) exemptions or 
floors, intended to eliminate monitoring costs of "nonfruitful" populations. Examples include exemptions for businesses with less than a certain number of employees or floors on deductible expenses. Although our eventual goal is to provide operational rules for the design of both kinds of presumptive taxes, in this paper we begin that task by analyzing an important example of the second type of presumptive tax - the standard deduction in the U.S. individual income tax system.

\section{The optimal standard deduction}

The standard deduction is, in terms of dollars involved, probably the most important presumptive element in U.S. individual income system. Under it, taxpayers can choose either to itemize their qualifying deductions and subtract the total from taxable income or to claim a standard deduction that varies only by filing status. As of tax year 1991, the standard deduction for married couples filing jointly was $\$ 5,700$; for single filers it was $\$ 3,400$. In 198870.9 percent of taxpayers claimed the standard deduction, with the fraction declining as income rises. Of those with incomes between $\$ 10,000$ and $\$ 20,000,88.9$ percent took the standard deduction; of those with income between $\$ 100,000$ and $\$ 150,000$, only 5.7 percent used the standard deduction.

The standard deduction fits well into the presumptive tax framework because its magnitude trades off compliance cost and another desirable characteristic of tax systems-in this case, horizontal equity. A higher standard deduction means that fewer taxpayers will itemize deductions, reducing the compliance cost of calculating and documenting the expenses as well as the administrative cost of monitoring the claimed deductions. The cost of a higher standard deduction is that for more people the tax system bases tax liability on something other than income net of actual deductions, which we will assume is the preferred measure of ability to pay. ${ }^{1}$

\subsection{The individual's problem}

We first model the individual's problem and then turn to the government's problem. Each individual has gross income of $r$, and potentially itemizable deductions of $e$. Real before-tax income is simply $r-e .^{2}$ In the tax filing process, the individual has a choice of itemizing deductions; in this case taxable income is $r-e-c$, where $c$ is the cost of keeping and assembling the records needed to justify itemization. It is assumed that $c$ is a deductible expense. ${ }^{3}$ Alternatively, the taxpayer can take a standard deduction equal to $s$, so that taxable income is $r-s$. Clearly the taxpayer will take the standard deduction if $T(r-s)<$ $T(r-e-c)+c$, where $T$ is the tax function, and will itemize otherwise.

Let $e^{*}(r, s, c)$ be the value of itemizable deductions that make a taxpayer indifferent between the two options, so that $e^{*}$ is defined implicitly by $T\left(r-e^{*}-c\right)$ 
$+c=T(r-s)$. Linearizing the tax system in the neighborhood of $r-s$ allows us to approximate as follows:

$$
e^{*} \approx c(1-\tau(r-s)) / \tau(r-s)+s,
$$

where $\tau$ is the marginal tax rate. Clearly $e^{*}>s$ as long as $1>\tau>0$ and $c>0$. Itemizing becomes attractive only if the tax savings, relative to the standard deduction, are high enough to offset the net-of-deduction compliance cost of itemizing. Note, for later use, that using the implicit definition of $e^{*}$ we can establish that

$$
\frac{d e^{*}}{d s}=\frac{\tau(r-s)}{\tau\left(r-e^{*}-c\right)} \geq 1 .
$$

\subsection{The government's problem}

For any given tax function, an increase in the standard deduction has four effects: it (1) reduces tax revenue, (2) reduces aggregate compliance costs, (3) reduces aggregate administrative costs (to be introduced below), and (4) sacrifices horizontal equity (reduces the ability of the tax system to distinguish tax liability on the basis of ability to pay, which in this model is assumed to be $r-e$ ). Compared to full deductibility, a standard deduction favors taxpayers with small expenditures.

It is a formidable challenge to introduce the social cost of horizontal inequity in a way that is both conceptually appealing and analytically tractable. Our solution to this challenge is to use the following measure of the deviation of a tax system from horizontal equity (DHE):

$$
\operatorname{DHE}(s)=E\{|y(r, e, T(r, e))-y(r, e, T(r, e, s))|\}
$$

where $y(r, e, T(r, e))$ is after-tax income without a standard deduction and $y(r, e$, $T(r, e, s))$ is after-tax income when the standard deduction is allowed. Since taxpayers with $e>e^{*}$ will itemize, (3) can be restated as

$$
\operatorname{DHE}(s)=\int_{0}^{\infty} \int_{0}^{e^{*}}[c+T(r-e-c)-T(r-s)] f(e, r) d e d r
$$

where $f(e, r)$ is the joint density function of $e$ and $r$.

$\operatorname{DHE}(s)$ measures the average (or aggregate) absolute deviation of tax liability under a tax system with a standard deduction from one that has no standard de- 
duction. Thus it measures horizontal inequity as the deviation from a standard where tax liability is based on "true" income, holding $T()$ constant ${ }^{4}$

Note that, in this example, DHE compares two tax systems that raise different amounts of revenue. (To do revenue-neutral comparisons, we would have to specify how the lost revenue is made up and investigate the horizontal-equity implications of the revenue offsets.) In fact, in this case DHE happens to equal the revenue lost (plus compliance cost incurred) by instituting the standard deduction. However, this relationship of DHE to revenue loss will not hold if the policy examined imposes both tax increases and tax decreases. To pursue the relationship between DHE and revenue loss, consider a policy of coupling the increase in the standard deduction with a decline in the personal exemption that is available to the taxpayer, call it $x$. Under the American system subtractions from adjusted gross income to arrive at taxable income are not $\max (s, e)$, as has been assumed up to this point, but rather $x+\max (s, e)$, which is equal to $(x+s)+\max (e-$ $s, 0$ ), where $e-s$ is what during an earlier period was known as "excess itemized deductions." Using the terminology of that period, $x+s$ becomes the "zero bracket amount," call it $z$ (the level of income below which no tax liability is due, regardless of the level of potentially itemizable deductions). Now we can recast the problem as choosing $z$ and the threshold above that itemized deductions can be claimed, call it $b$, so that total deductions are $z+\max (e-b, 0)$. The problem of the optimal value of $b$ would be identical to the problem posed below in expression (5), where the standard for the appropriate tax base, in reference to which DHE is measured, is $r-e-(z-b)=r-(e+x)$. Contrary to the problem of choosing $s$, however, an increase in $b$ increases revenue because it raises revenue from itemizers and has no effect on nonitemizers.

Now returning to the $s$-setting problem, we posit that the government sets $s$ in order to minimize

$$
(a+c) \int_{0}^{\infty}\left(1-G\left(e^{*}\right)\right) h(r) d r+\lambda \mathrm{DHE}\left(e^{*}\right)
$$

where $G\left(e^{*}\right)=\int_{0}^{e^{*}(r)} f(e, r) d e$, the cumulative distribution of $e$, given $r, h(r)$ is the density function of $r$, and $a$ is the administrative cost per itemizing return of monitoring the claimed deductions. The first component of (5) is the sum of compliance and administrative costs of itemizing, which equals $a+c$ per itemizing return; there are $1-G$ itemized returns, where $G$ depends on the distribution of $r$ and $e$ as well as the values of $s$ and $c$. The second component of (5) is the social cost of the divergence from horizontal equity; the value of DHE is multiplied by the shadow social price of DHE, $\lambda$, where $\lambda$ is assumed to be a constant. 
Implicit in our framework is a two-stage government decision process. In the first stage the government chooses $T($ ) by solving a standard (that is, ignoring compliance costs) optimal progressivity problem. With $T$ chosen, it then confronts the tradeoff between saving on collection costs and sacrificing horizontal equity by abandoning the principle that two taxpayers with the same ability to payassumed to be $r-e$-should pay the same tax by announcing what level of the total deductions it will accept without documentation, $s$. In a more general model $T($ ) and the standard deduction would be chosen simultaneously so, for instance, any vertical equity implications of choosing $s$ can be offset by the choice of $T($ ).

By ignoring an overall revenue constraint, the problem as posed in (5) assumes that the government has other tax instruments to keep revenue constant; that excess burden depends on total revenue raised but not on which instruments are used to raise the revenue; and that the collection cost of the alternative instruments is zero. A generalization of these assumptions would be desirable but would take the problem into the next order of difficulty-a tradeoff among collection costs, horizontal inequity, and excess burden as traditionally defined.

The optimal value of $s$ trades off the saving in collection cost against the increase in DHE. The first-order condition for $s$ is

$$
(a+c) \int_{0}^{\infty} g\left(e^{*}(r)\right) \frac{d e^{*}}{d s} h(r) d r=\lambda \int_{0}^{\infty} \tau(r-s) G\left(e^{*}\right) h(r) d r,
$$

where $g\left(e^{*}\right)$ is the density function of $e$, given $r$. This expression simplifies considerably if the tax system is linear-that is, if $\tau$ is constant $(=t)$ for all levels of taxable income. In this case the dependence of $e^{*}$ and $\tau$ on $r$ can be ignored, so that $d e^{*} / d s$ is equal to one according to equation (2), and equation (6) becomes

$$
(a+c) f\left(e^{*}\right)=\lambda t F\left(e^{*}\right),
$$

where $f(e)$ and $F(e)$ are the unconditional density and cumulative contributions of $e$, respectively. ${ }^{5}$

Equation (7) has a straightforward interpretation. The left side is the marginal savings of collection cost due to increasing $s$, which is $(a+c)$ multiplied by the additional fraction of taxpayers who will choose the standard deduction because of the increase. The right side is the social cost of the increased divergence from horizontal equity, which is the social price per unit of divergence, $\lambda$, multiplied by $F\left(e^{*}\right)$, where $F$ is the fraction of taxpayers who take the standard deduction. Increasing the standard deduction by $\$ 1$ saves all current nonitemizers $\$ t$ in tax liability, which for that group represents an increase of $\$ t$ per nonitemized, or $t F\left(e^{*}\right)$, overall, in the divergence from a horizontally equitable tax burden. This interpretation also applies to the more general first-order condition of (6). 
Some comparative static exercises using this model are insightful. Consider first an exogenous decrease in the value of $t$ faced by the $s$-setting agency. This lowers the marginal DHE cost of increasing $s$ and increases the optimal value of $s .{ }^{6} \mathrm{Be}-$ cause a lower $t$ reduces the horizontal inequity of the standard deduction, it is optimal to expand it. Note that the rate-flattening U.S. Tax Reform Act of 1986 (TRA) was in fact accompanied by a substantial increase in the real value of the standard deduction; this behavior is consistent with the prescriptions of this model.

TRA also pared the deductions that qualify for itemization. Holding $t$ constant, that has two effects on the optimal standard deduction. First of all, it decreases the resource cost of itemizing, $(a+c)$; this would unambiguously decrease the optimal value of $s$ because it would reduce the collection-cost-reduction advantage of the standard deduction without reducing the horizontal inequity of a given standard deduction. Second, disqualifying some deductions also changes the distribution of potentially itemizable deductions. This affects both the marginal benefit and marginal cost of changing $s$, as is clear on inspection of equation (6) or (7). If $f^{\prime}$ is everywhere negative, then the marginal benefit of increasing $s$, which is proportional to the number of taxpayers with potential deductions at that level, is lower for any given value of $s$. In addition, because there are more nonitemizers at any level of $s$, the marginal cost of raising $s$ is higher. Thus this second aspect of disqualifying certain deductions also suggests a lower optimal value of $s$.

\section{Applications of the model}

Making this model operational requires knowledge of three things: the joint distribution of $r$ and $e$, the resource cost of itemization, $a+c$, and the shadow price of the divergence from horizontal equity, $\lambda$. There is abundant microdata to estimate the first; although the data on deductions is available only for those taxpayers that actually do itemize, standard censored-sample estimation techniques can produce a reasonable picture of the overall distribution. The compliance cost of itemization can be approximated through taxpayer surveys or by structural estimation of the itemization decision, as in Pitt and Slemrod (1989).

The most problematic element of the model is the shadow value of a unit of divergence from a horizontal equity standard, $\lambda$, which is not observable. The current model can be used to calculate what the implicit value of $\lambda$ must be if the observed standard deduction is in fact the optimal solution to the problem we have posed, assuming $f()$ and $a+c$ are known. ${ }^{7}$ To do so, we can take advantage of the fact that Pitt and Slemrod (1989) have estimated that in 1983, for those taxpayers at the margin between itemizing and taking the standard deduction, the average private-income cost of itemizing deductions was about $\$ 30$. Because some of these costs are deductible, the social cost is somewhat higher. Furthermore, there are monitoring costs borne directly by the tax enforcement agency. 
As an estimate of $a+c$, let us begin by doubling the figure from Pitt and Slemrod, yielding \$60 per itemizing return. Based on simulations using the Office of Tax Policy Research tax simulator, the average value of $t$ for marginal itemizers in 1983 was 0.2. Pitt and Slemrod calculate that increasing the standard deduction by $\$ 1,000$ would decrease the number of itemizers by 6.8 million. According to our assumptions, this would save resource costs equal to $\$ 60$ multiplied by 6.8 million, or $\$ 408$ million. The DHE (in this case equal to the revenue cost) of this policy is $\$ 100 \times 6.8$ million, or $\$ 680$ million, for the former itemizers who now take the standard deduction, ${ }^{8}$ and $\$ 200 \times 73.4$ million, or $\$ 14.68$ billion, for those 73.4 million taxpayers who continue to take the standard deduction, for a total of $\$ 15.36$ billion. ${ }^{9}$ Thus the 1983 level of the standard deductions was optimal if $\lambda$ equals $\$ 0.408$ billion/ $\$ 15.36$ billion, or 0.026 ; if $\lambda$ is greater than 0.026 , increasing the standard deduction is not an appropriate tax reform. In this case decreasing the standard deduction would be appropriate because the decrease in DHE would more than offset the resource cost of more itemizers.

A more modest goal is to assess whether the various presumptive elements of a given tax system are consistent with a common shadow value of $\lambda$. As an example, consider the deduction under the U.S. income tax system for extraordinary medical expenses. Under current law, qualifying medical expenses in excess of 7.5 percent of adjustable gross income can be claimed as a deduction, if the taxpayer chooses to itemize deductions. The choice of the 7.5 percent floor for deductions should reflect the same tradeoffs between compliance and administrative costs, on the one hand, and horizontal equity on the other (that is, the same $\lambda$ ), as does the choice of the standard deduction. Note that in the medical expense case, it is those with expenses below the floor who, from a horizontal equity standpoint, have too high a tax liability; with the standard deduction, those with low deductions - but who claim the standard deduction-get too low a tax liability according to our horizontal equity standard.

\section{Conclusion}

Whether it is explicit or implicit, all tax systems must trade off the accuracy of tax-base measurement against the cost of that measurement. In many developing countries, how this tradeoff is solved is explicit in the use of presumptive tax base measures, which are relatively easy to ascertain although not otherwise ideal tax bases. The same tradeoff is implicit in many elements of the tax systems of developed countries, although the terms of these tradeoffs have not been given much attention in academic models of optimal tax policy.

This paper offers a stylized model for making these tradeoffs. It appeals to a simple measure of horizontal inequity and pursues the normative implications of this measure. Its goal is to stimulate thinking about the tradeoff between minimizing collection costs and achieving other goals of tax systems. 


\section{Acknowledgments}

This paper was prepared for the Conference on Tax Administration and Tax Policy, cosponsored by the International Seminar in Public Economics and the Instituto de Estudios Fiscales, held in Escorial, Spain on June 11-12, 1992. We would like to thank the participants at that conference-particularly James Alm, Maurice Marchand, and Jonathan Skinner-for helpful comments on an earlier draft. Three referees and the editors of this journal also provided many valuable suggestions.

\section{Notes}

1. A higher standard deduction (accompanied by a surtax that keeps revenue constant) is often associated with a more progressive tax system. However, a floor in income below which no tax liability exists could just as well be established by a personal exemption, while still allowing all deductions to be itemized.

2. We do not question the validity of allowing these deductions in arriving at a proper measure of ability to pay. In practice some deductions, such as charitable contributions, are better characterized as incentive programs rather than adjustments to better measure net income. We also ignore the possibility that the deduction amount itself is responsive to whether it is deductible.

3. To the extent that compliance cost is comprised of the taxpayer's time, it would not be deductible. This would change the implicit definition of $e^{*}$ to $T\left(r-e^{*}\right)+c=T(r-s)$, implying that equation (1) be $e^{*} \approx C / \tau(r-s)+s$. The qualitative conclusions of the paper would not be altered.

4. The DHE concept differs from the earlier literature's emphasis on rerankings as an index of horizontal inequity. See, for example, Feldstein (1976), King (1983), and Plotnick (1981). For a criticism of the reranking criterion, see Kaplow (1989). We do, though, accept the premise of the reranking literature that an anonymous social welfare function does not adequately capture the point that a capricious fiscal system is something to be avoided, per se. Our concept of DHE stands outside of the social welfare function approach because it presumes that income changes due to deviations from the optimal government tax and transfer policy (not considering compliance costs) are qualitatively different (and worse) than an exogenously imposed, but otherwise equivalent, set of changes in income.

5. To see whether the second-order conditions are satisfied for a given distribution, note that we can rewrite (7) as $f\left(e^{*}\right) / F\left(e^{*}\right)=\lambda t /(a+c)$, where the right side is a constant. Since a typical $f()$ is first increasing and later decreasing, one is assured that the left side is a declining function of $e^{*}$, at least for high $e^{*}$. In general, there is no assurance of a unique global optimum.

6. This, and other, comparative static results depend on the second-order conditions of the government maximization problem holding. For (7) to characterize an optimum, it must be true that $\lambda t f\left(e^{*}\right)>(a+c) f^{\prime}\left(e^{*}\right)$. A sufficient condition for this holding is that $f()$ is constant or declining.

7. Using the normative model to recover social values has been attempted in the context of vertical equity decisions in the previous literature. See, for example, Mera (1969).

8. With a marginal tax rate of 0.2 , a $\$ 1,000$ deduction provides a tax reduction of $\$ 200$. If the tax saving of those who switch from itemizing is uniformly distributed among the 6.8 million switchers, it averages to $\$ 100$.

9. This assumes a marginal tax rate of 0.2 for all nonitemizers, which is likely to overestimate the true average. 


\section{References}

Blumenthal, Marsha, and Joel Slemrod. (1992). "The Compliance Cost of the U.S. Individual Income Tax System: A Second Look After Tax Reform." National Tax Journal. (June) 45, 185 202.

Feldstein, Martin. (1976). "On the Theory of Tax Reform." Journal of Public Economics (JulyAugust) 6, 77-104.

Kaplow, Louis. (1989). "Horizontal Equity: Measures in Search of a Principle." National Tax Journal. (June) 42, 139-154.

King, Mervyn. (1983). "An Index of Inequality: With Applications to Horizontal Equity and Social Mobility." Econometrica (January) 51, 99-115.

Mayshar, Joram. (1991). "Taxation with Costly Administration." Scandinavian Journal of Economics $93,75-88$.

Mera, Koichi. (1969). "Empirical Determination of Relative Marginal Utilities." Quarterly Journal of Economics (August) 83, 464-477.

Pitt, Mark, and Joel Slemrod. (1989). "The Compliance Cost of Itemized Deductions." American Economic Review (December) 79, 1224-1233.

Plotnick, Robert. (1981). "A Measure of Horizontal Equity." Review of Economics and Statistics 63, 283-288.

Sadka, Efraim, and Vito Tanzi. (1993). "A Tax on Gross Assets of Enterprises as a Form of Presumptive Taxation." Bulletin of International Fiscal Documentation (February) 47, 66-73.

Sandford, Cedric, Michael Godwin, and Peter Hardwick. (1989). Administrative and Compliance Costs of Taxation. Bath: Fiscal Publications.

Sandmo, Agnar. (1981). "Income Tax Evasion, Labor Supply and the Equity-Efficiency Tradeoff." Journal of Public Economics (December) 16, 265-288.

Slemrod, Joel, and Nikki Sorum. (1984). "The Compliance Cost of the U.S. Individual Income Tax System." National Tax Journal (December) 37, 461-474.

Slemrod, Joel, and Shlomo Yitzhaki. (1987). "The Optimal Size of a Tax Collection Agency." Scandinavian Journal of Economics (September) 89, 183-192.

Tanzi, Vito, and Milka Casanegra de Jantscher. (1989). "The Use of Presumptive Income in Modern Income Tax Systems." In Aldo Chiancone and Kenneth Messere (eds.), Change in Revenue Structures: Proceedings of the 42nd Annual Congress of the International Institute of Public Finance held in Athens, Greece, 1986. Detroit: Wayne State University Press.

Usher, Dan. (1986). "Tax Evasion and the Marginal Cost of Public Funds." Economic Inquiry (October) 24, 563-586.

Wilson, John D. (1989). "On the Optimal Tax Base for Commodity Taxation." American Economic Review (December) 79, 1196-1206.

Yitzhaki, Shlomo. (1979). "A Note on Optimal Taxation and Administrative Cost." American Economic Review (June) 69, 475-480. 